\title{
Second Language Acquisition Theory Based Bilingual Teaching Methods of Computer Science
}

\author{
Fumin Ma \\ College of Information Engineering \\ Nanjing University of Finance and Economics \\ Nanjing, China 210023
}

\author{
Jingwen Chen \\ College of Information Engineering \\ Nanjing University of Finance and Economics \\ Nanjing, China 210023
}

\begin{abstract}
According to the characteristics of computer science, the second language acquisition theory based bilingual teaching methods under credit system was studied. The main factors that influence the learning motivation of bilingual teaching under credit system are analyzed firstly, and the learning motivation stimulating methods are also discussed; Secondly, the curriculum setting and materials selecting principles for bilingual teaching are investigated to meet the specialty demands; finally, an interactive and heuristic student-centered bilingual teaching mode is constructed. The bilingual teaching efficacy of computer bilingual courses was improved gradually through the exploration of the bilingual teaching methods based on second language acquisition theory in view of the discipline characteristics.
\end{abstract}

Keywords-second language acquisition theory; bilingual teaching; computer science

\section{INTRODUCTION}

In order to adapt the development of economic globalization and domestic higher education internationalization, strengthening the bilingual teaching of undergraduate general and specialized courses is indispensable. Computer science is a typical representative of the most common subject in the world with English as new technology carrier and the developed countries in Europe and US as top runner. Therefore, Carrying out bilingual teaching in computer science is very suitable $[1,2]$. However, students have much more autonomy in course selection under the current credit system management mode. Moreover, some students for whom English is a second language, with weak English foundation and insufficient understanding on the necessity and importance of the bilingual teaching, may be afraid of bilingual courses that may lead to overburden studying and difficult credit achieving. How to guide students to select bilingual courses, how to deal with the relation between professional knowledge teaching and students professional English level improving, and how to improve the bilingual teaching efficiency on the premise of ensuring the professional teaching quality have still been one of the heating focuses in higher education research.

In recent years, Second Language Acquisition (SLA)

Supported by the Education Research Foundation of Nanjing University of Finance and Economics (JGY1746). proposed by American linguist Krashen is the most influential theory among second language acquisition researches. And it provides the important methodology guidance for the second language teaching [3].

Subject characteristics and language ability acquisition general rules should be followed in bilingual teaching reform Combining with our bilingual teaching experiences, "Five Hypothesis" of second language acquisition theory was found to be a certain guidance and reflection for above questions that students and teachers are confronted with in bilingual teaching. The computer bilingual teaching methods under credit system was explored based on Krashen's second language acquisition theory, some frameworks and methods for the design of bilingual teaching program and teaching practice were put forward.

\section{LEARNING MOTIVATION STIMULATING METHODS AND STUDY CONCENTRATION IMPROVING MEANS}

\section{A. Some Factors Resulting in Negative Learning Motivation}

The target of computer bilingual teaching is to use English for professional courses teaching and learning, which equip students with certain reading ability for professional English materials after several training stages. According to Krashen's "emotional filtration hypothesis" theory, students, as the study subject, their learning motivation plays an important role in the bilingual teaching effect [4]. Therefore, stimulating the positive learning motivation of students is the primary condition to ensure the quality of bilingual teaching and to achieve the bilingual teaching goal.

Some factors lead to the negative learning motivation of students in bilingual teaching, as follows.

- Brain fatigue may easily be caused during the bilingual teaching of computer professional courses, especially for students with weak English foundation. Besides, for the necessity of bilingual teaching, some students have the insufficient understanding, such as heavy study burden, hard credits acquisition and so on, which will result in the students' difficult mentality for bilingual courses. Moreover, students has considerable autonomy in course selecting under 
credit system, the negative learning motivation will be easily produced in computer professional course teaching.

- The bilingual teaching ability of teachers is also important factor that affect students' learning motivation. Through a survey of some students majored in computer, $87 \%$ students indicated that they would get to know the bilingual teaching level of teachers from the web or alumni, and $73 \%$ of them would consider these information as decision-making factors in the course selecting. However, in some colleges, there are not so many qualified bilingual teachers who are equipped with both professional computer science knowledge and high level of English that is adequate for computer knowledge expression and communication. Some teachers even mistakenly treat bilingual courses as a professional English course; emphasize solving language problems in the class so that students feel like they are in the English translation course2]. This not only results in the damage of teaching objectives, but also the negative learning motivation of students.

- Grade evaluation mode of computer bilingual course is still very monotonous under credit system, which still adopts a test paper to determine student performance. As long as the students pass the exam, they all get the same credits regardless of their different scores in exam. However, many computer courses emphasize application. The practical application ability cannot be tested by the monotonous paper testing evaluation mode, which also influences the learning motivation.

\section{B. Some Methods Stimulating Learning Motivation}

The learning process of bilingual courses in computer science is also an input and output process of language. Krashen's "input hypothesis" argues that the input of higher level language, contrasted with current level, is an important condition for second language acquisition. Let learner's existing second language level defined as "i" and the higher level of language that the learner will achieve defined as " $i+$ 1 ", the gap between " $\mathrm{i}$ " and " $\mathrm{i}+1$ " is the driving force of learning. Therefore, during the bilingual teaching of computer science, teaching methods should be explored and innovated constantly from the following aspects with the consideration of the unique characteristics of computer specialty.

- Bilingual teaching in computer science is not simple to teach student computer English. More importantly, it aims at creating a win-win situation between English and professional knowledge. Therefore, the teachers should make more efforts to every part of computer professional bilingual courses, and also keep improving their academic competency, language skills and organizational skills.

- " 1 " should be quantitatively controlled well on the basis of individual personality, learning attitudes, learning methods and differences of academic performance. It means that students' enthusiasm would be prevented if the input knowledge to them is too simple or beyond their comprehension ability. Furthermore, students' affective filter in professional computer bilingual course should be minimized through some incentive measures, which can improve students' attention in professional bilingual curriculum learning, and promote students gradually form an active learning attitude.

- It is necessary to take some measures to reform the traditional way of assessment constantly, such as laying stress on students' professional computer application ability and actual English level improvement, scattering students' assessment to daily learning process, diversifying assessment methods and increasing the proportion of normal performance. In addition, different credits can be given to students according to their final assessments.

\section{BILINGUAL CURRICULUM AND TEACHING MATERIALS SELECTION IN ACCORDANCE WITH COMPUTER SCIENCE FEATURES}

In fact, not all the subjects of computer science are suitable to be set as bilingual courses. Furthermore, single bilingual course teaching is lack of continuity and integrity, which may result in less system acquisition opportunities of professional English and the splitting of professional knowledge. Besides, as the professional courses of computer science, only if other preorder courses have been attended, can many courses be set. That is to say, both the rationality of course arrangement can directly influence the teaching effectiveness. Therefore, the pre-and-post connection between courses must be considered when it comes to computer bilingual teaching. Meanwhile, students' acceptance ability should be also taken into account [5-7].

According to the characteristics of computer science, professional bilingual courses can be set by the following rules:

- Computer programmable course: This kind of course has strong international universality and uses English as carrier of new emerging relevant professional knowledge. The original compiling environment is also developed based on English, and programming language is full of English instruction and command. Thus, this kind of course is very suitable for bilingual teaching.

- Easily understood or visualized Course: With graphic representation or other visualized expression methods, this kind of course, such as Computer Network, Internet Technology, etc., is more easily to be described in teaching process. Students' comprehension on professional knowledge would be enhanced and knowledge comprehension barriers caused by insufficient English would also be alleviated. But if the course knowledge is too abstract to understand for students, like Computer Composition Principle, adopting bilingual teaching 
will make the students face multiple difficulties including professional technical knowledge, English speaking and listening.

- The course with Prior knowledge taught in the preorder courses: For this kind of course, the similar knowledge points has been learned ever, students would understand knowledge quickly if bilingual teaching is given.

Apart from the bilingual course arrangement, the teaching effect will also be influenced by the professional material selection. Krashen's "input hypothesis" and "affective filtration hypothesis" show that the input of language knowledge, which would be received consciously or unconsciously by learners, is massive and infinite. The intake of language input depends on various factors, but mainly is learners' affective variables. The excellent original English edition has become an ideal choice for bilingual teaching due to many advantages such as accurate language, rich knowledge, step-by-step explanation, concise and clear structure etc., which may ensure students to accept enough higher knowledge compared with their present level. Therefore, outstanding original teaching materials should be chosen as much as possible in accordance with computer science characteristics.

Considering the difference between oriental and occidental thinking mode, the basic theories and skills should be emphasized rather than fully replication and the teaching content selection from original English teaching materials should be reasonable and highlight the key points.

\section{THE STUDENT-CENTERED INTERACTIVE AND Heuristic BiLingual TEACHING Mode}

In Krashen's second language acquisition theory, "acquisition-learning hypothesis" located the first place among five hypotheses which suggested that there are two independent ways containing "acquisition" and "learning" to develop the ability of second language. As known, acquisition is a subconscious process which is consistent with the process of child acquiring mother tongue. During this process, language is usually acquired unconsciously by learner. On the contrary, learning is a conscious process and means clear understanding of a second language. Krashen holds that acquisition is more important than learning in the use of second language. Acquisition takes listening as important source. Second language learner generally experiences a silent period at the beginning, and then can be in harmony with expression after accepting plenty of inputs.

The most major problem in computer bilingual teaching is that students' comprehension on professional knowledge would be influenced by teaching in English. The understanding of second language vocabulary and professional knowledge is a conscious process in the beginning. And thus, compared with mother tongue teaching, the different degree of hysteresis would occur during the classes. To avoid students' learning interest lost, teachers are asked to provide students more relevant language input during the teaching process, and keep reminding learners the important points. Moreover, teachers are also required to create acquisition conditions which gradually change students from definite learning to unconscious acquisition and make students master computer professional skills unconsciously during the second language acquisition process.

Based on "monitor hypothesis" in second language acquisition theory, learners were divided into three kinds by Krashen: "over monitor learner", "lack monitor learner" and "reasonable monitor learner". The so-called "reasonable monitor learner" is to use monitor means in appropriate situation without impacting language communication. Furthermore, Students not only be encouraged to ask question at any time but also be given performance opportunities through interactive and heuristic bilingual teaching mode. Let students discover problems and monitor their learning process, and then transit from "over monitor learner" or "lack monitor learner" to "reasonable monitor learner", from nonspeaking to active speaking. Meanwhile, during the interactive and heuristic bilingual teaching process, the English thinking mode would be deepen gradually, which help students not only master the language expression, but also master the specialized technical knowledge.

\section{CONCLUSION}

The bilingual teaching methods of computer professional courses were explored in this paper. The main factors affecting the learning motivation of bilingual teaching under credit system were analyzed firstly, and then the learning motivation stimulating methods in bilingual teaching based on "input hypothesis" and "affective filter hypothesis" in second language acquisition theory were discussed. According to the characteristics of computer science, the curriculum and textbook selecting principles for bilingual teaching were given. Finally, a student-centered interactive and heuristic bilingual teaching mode was established under "acquisition-learning hypothesis" and "monitoring hypothesis" in second language acquisition theory. With the extensive implementation of computer bilingual teaching in universities, there will be many experiences brought and also many problems worthy further study.

\section{REFERENCES}

[1] Bai, Xuemei, Y. Lu, and J. Su. "Research on the Bilingual Teaching in the University," International Conference on Education, Management, Computer and Society Atlantis Press, 2016.

[2] Chapelle, Carol A. "The Relationship between Second Language Acquisition Theory and Computer-Assisted Language Learning," Modern Language Journal 93.Supplement s1(2009):741-753.

[3] Valdés, Guadalupe, L. Poza, and M. D. Brooks. Language Acquisition in Bilingual Education. The Handbook of Bilingual and Multilingual Education, 2015.

[4] Wang, Zhijian, and J. Zhang. "Factors Influencing Bilingual Teaching on Computer Science," Advances in Computer Science, Intelligent System and Environment DBLP, 2011:519-523.

[5] Yang, Yi, and L. Yan. Personalized Design on Bilingual Teaching of Computer Science in Chinese Universities. Advances in Information 
Technology and Education. Springer Berlin Heidelberg, 2011:407412.

[6] Qin, Yi Qing. "Bilingual Teaching Practice on Computer Science," Modern Educational Technology, 2007, vol. 17, no.11, pp. 105-107.

[7] Fan, Yutao. "Study on Construction of Bilingual Teaching System in Computer Science and Technology Major," Computer Education, 2011, no. 24, pp. 50-53.

[8] Wang, Limin, X. Han, and S. Zhang. Research on Bilingual Teaching Reform of Undergraduate Computer Courses in Financial and Economical Colleges. IEEE Computer Society, 2009. 